\title{
The Economics of Suicide
}

Damian Valery Praveen Miranda \& Hrishikesh Pande

'On April 8th 1994 Kurt Cobain, the lead singer of Nirvana, was found dead in his Seattle home of an apparent shotgun wound to the head and with three times the lethal amount of heroin in his system. A note lay at the scene. The verdict was suicide. Others are sceptical.' (from www.deathofkurtcobain.com)

In the pall of gloom surrounding Michael Jackson's recent death when we read this extract from a site dedicated to Kurt Cobain, a number of questions struck us as being interesting. Why do famous celebrities commit suicide? Could the reasons be monetary, social or some other phenomenon? Why would such renowned personalities give up an apparent life of luxury?

In furthering our understanding of these issues it strikes us as pertinent to ask whether we can ever view suicide from the perspective of an economist. Can we assess human behaviour pertaining to suicide using the rational science of economics or are we treading on unknown territory in psychiatry instead?

Consider a quote by the famous economist Gary Becker from his book The Economic Approach to Human Behaviour'

"Good health and a long life are important aims of most persons, but surely no more than a moment's reflection is necessary to convince anyone that they are not the only aims: somewhat better health or a longer life may be sacrificed because they conflict with other aims ... According to the economic approach, therefore, most (if not all!) deaths are to some extent "suicides" in the sense that they could have been postponed if more resources had been invested in prolonging life." (Becker, 1976)

This is a fascinating perspective and it suggested to us the significance of the concept of opportunity cost when placing a value to a human life. 


\section{Introduction}

In this paper we look at the value placed on life through the eyes of an economist. Simply, in the context of social and political sciences, the value of life is 'a marginal cost of avoiding death'. This is, however, a controversial and complex issue because there is no commonly accepted measurement mechanism for the valuation of life. Not everyone values his or her lives in terms of money. However, this approach is not entirely about money. There are different school of thoughts prevailing in this area of research. Some economists, as the quote by Gary Becker above illustrates, suggest measuring the value of life in terms of the cost a person is willing to pay to avoid the risk of death.

The characteristics of the various aspects of life that add value to it are too diverse and complicated. It is therefore very difficult to gauge the length of every stream of these aspects that would add value to human life. A simpler method of valuing life would be to observe the phenomenon of life in the perspective of an individual's mental and physical complacency. However, quantifying the value of happiness is a complicated process, since each individual derives levels of happiness in different scales for a given occurrence. These difficulties compound as we engage in the economist's penchant from marginal analysis in trying to enumerate the additional utility of happiness. Therefore, we asked ourselves the more philosophical question of what it is that makes us happy.

Perhaps necessities would satisfy ones needs. However, are needs the only thing humans desire? Happiness is more than a satisfaction of needs. Admittedly the fulfilment of needs is associated with the achievement of a large quantum of marginal utility. We can probably say that this amount of consequent marginal utility equals the amount of happiness. Therefore, the human life is a pursuit of quantum changes in marginal utility that will eventually provide a greater fulfilment.

However, the opposite would also hold true when both wants and needs are not satisfied. It is disappointing to a person when he or she fails to achieve a change in marginal utility that surpasses the quantum changes achieved previously or, indeed, by others in society. 
This would create an emotional and physical strain which would be directly proportional to the emphasis the individual places on the quality of life. The more we want and the more we achieve the greater would be the quality of life. This would create a positive relationship between happiness and the standard of life.

Thus, the standard of life hitting rock bottom is intrinsically linked to the marginal utility of happiness also decreasing. This incipiently develops a melancholy that results in an unhealthy mental and physical state leading the individual to contend with the question of 'to be or not to be?' or ponder an 'existential dilemma'. That is, to bear these pressures or just quit.

"Suicide is not chosen; it happens when pain exceeds resources for coping with pain." quotes Metanoia, an online counselling, resource centre and support organization that helps people deal with their suicidal thoughts. Therefore, when one senses scarcity of resources, like the resources to live life happily or mental resources such as social confidence, he chooses to end his life. There are biological explanations to this outcome avers Metanoia on its site suggesting that a person who commits suicide generally lacks a chemical called serotonin in the brain. (www.metanoia.org/suicide)

\section{Heartbreaking News}

If we observe the empirical trends and try to describe the common cause of suicide, we would very likely infer it to be unhappiness. It seems obvious that happy people are less likely to commit suicide, as a higher level of happiness should create a stronger and healthier mental state. Indeed, many observations have indeed shown mental depression to be a strong explanatory factor for suicide.

Among farmers in India there has been an alarming increase in the number of suicides throughout this decade. In the state of Maharashtra, indebtedness, poor living conditions, damaged health, social and familial obligations, addiction, crop failure were found to be the 
chief causes, and, unsurprisingly, all are strongly associated with being unhappy (Government of Maharashtra, 2006).

The statistics on suicidal deaths for European countries tell us a different story. Switzerland, which is the third richest country in the world on a per capita basis, recorded 1300 suicidal deaths in 2005. In some other so-called 'financially stable' countries the rate is increasing. Therefore, suicidal thoughts do not seem to be discriminating between people based on their wealth and social relations alone. (Workman, 2009 and WHO, 2005)

The question therefore took a different trajectory in our mind - Why would people in upper-class societies place less value on their lives? Don't they like being rich? Do they have too much pressure to handle their wealth or is it just because they have nothing much left to achieve that gives them a satisfying quantum of marginal utility from life? Generally, why do they commit suicide?

The concept of opportunity cost might help us to understand this to a certain degree. When individuals belonging to the upper class choose to end their lives, the opportunity cost would be higher because they are giving away all the happiness and luxury they could have enjoyed by living life. Conversely, in the case of a poor farmer the opportunity cost may be negligible perhaps because he or she might have numerous debts. The farmer sees no happiness in living a life burdened with trouble.

The concept of lowering opportunity cost pertains to the choice made among a set of given options that gives a consumer the highest value in terms of the utility the consumer derives from it. The same applies to the value of life. In what way can we obtain maximum utility or pleasure compared to the alternative choice of not living? So when situations arise where people are blessed with many luxuries, but are not content with what they have, it is conceivable that the value they place on life decreases relative to death. 
Humans have a tendency to want more in life. This behaviour is a natural instinct, common to most humans. It is a tendency that leads them to appreciate life only when the marginal utility of living keeps on increasing. When the gains in marginal utility decrease or even come to a halt, the value placed on life starts to decrease as well.

The decrease in the relative value of happiness leads to the state where the mind is affected. People have varied mental capacities therefore the effects bear differently on various individuals. Two extreme phenomena can be observed. Some strive hard to overhaul the situation and continue with the choice of life. On the contrary, others are overwhelmed by the situation. Their mental state determines the end outcome.

This phenomenon would apply no differently to individuals in the lower income levels of society. When the marginal utility of life is low or perhaps even negative, the opportunity cost placed on life would increase. This decreasing marginal utility and increasing opportunity cost makes suicide a stronger option.

\section{Some concluding thoughts}

Let us consider what factors can detour a person from entertaining suicidal thoughts. What might the life-saving pill be? Perhaps it is in the pursuit of unexplored activities that can increase the value of their life by giving them the quantum of positive marginal utility they need. These might be taking part in sports or recreational activities, motivational self-help programmes, practicing spirituality, etc. Such practices would enable that additional utility and hence would increase the opportunity cost of death.

On the contrary, what of those situations that arise where a person would willingly forgo a longer life span to achieve higher present marginal utility? For instance, a person may derive a higher marginal utility voluntarily through a pack of smokes at the cost of shortening the length of his life. Is this seemingly suicidal behaviour placing a lesser value on life? Perhaps it can be argued that a longer life may not always enable deriving the highest utility in present value terms. The most important insight appears to be about the choices we make in deriving happiness. 
In Aristotle's words

"The ultimate value of life depends upon awareness and the power of contemplation rather than upon mere survival."

\section{References}

- Ainsworth M., 'Suicide: Read this First', Metanoia, accessed $14^{\text {th }}$ July 2009, <http://www.metanoia.org/suicide/>

- Becker, G. (1976) Economic approach to human behavior, University of Chicago Press, chicago.

- Government of Maharashtra, Farmers suicides in Maharashtra an overview (2006), <http://www.maharashtra.gov.in/english/chiefminister/Farmers_suicide_in_maha rashtra.pdf>

- The Death of Kurt Cobain, accessed $7^{\text {th }}$ June 2009, < http://www.deathofkurtcobain.com/>

- Workman D., Worlds richest countries, 10 July 2009, <http://internationaltrade.suite101.com/article.cfm/world_s_richest_countries>

- World Health Organisation, Suicide rates (2005), <http://www.who.int/mental_health/media/swit.pdf> 